\title{
Restoring balance: How history tilts the scales against privacy. An Actor-Network Theory investigation
}

\author{
Bill Bonner $^{\mathrm{a}, *}$ Mike Chiasson $^{\mathrm{b}}$, Abhijit Gopal ${ }^{\mathrm{c}}$ \\ ${ }^{a}$ Faculty of Business Administration, University of Regina, 3737 Wascana Parkway, Regina Saskatchewan, Canada S4S 0A4 \\ ${ }^{\mathrm{b}}$ Department of Management Science, Lancaster University Management School, Lancaster, United Kingdom LA1 4YX \\ ${ }^{\mathrm{c}}$ Richard Ivey School of Business, University of Western Ontario, 1151 Richmond Street North, London, Ontario, Canada N6A $3 K 7$
}

\section{A R T I C L E I N F O}

\section{Article history:}

Received 14 August 2007

Received in revised form 28 November 2008

Accepted 4 December 2008

\section{Keywords:}

Privacy

Balance

Actor-Network Theory

History

Historical investigation

Fair information principles

\begin{abstract}
A B S T R A C T
In this paper we problematize the metaphor of balance employed in the area of information privacy. Using Actor-Network Theory we conduct an historical investigation into the continuous release of the same personal data over the course of eight decades. Through the examination of actual enactments of balance over time we find that, in practice, balancing acts are conducted at local levels by local actor-networks within organizations, with limited overall organizational knowledge, raising challenges around interpreting statements made by organizational spokespersons. We also find a surprising lack of knowledge possessed by these local actornetworks about what is subsequently done with personal data and the extent to which networks that extend beyond the organization gravitate towards and form around available data. Through tracing and revealing this historical Actor-Network Theory investigation provides a means of probing and examining actual acts of balance in the area of information privacy and, through revelation, aid in the creation of the possibility of bringing the act of balance more in line with the concept.
\end{abstract}

(c) 2009 Elsevier Ltd. All rights reserved.

\section{Introduction}

Privacy is and has been a subject of interest to fields as diverse as psychology (Schwartz, 1968), sociology (Rule, McAdam, Stearns, \& Uglow, 1980; Winner, 1996), law (Solove, 2007; Warren \& Brandeis, 1890), history (Flaherty, 1972; Westin, 1967) political science (Bennett, 1990) and philosophy

\footnotetext{
* Corresponding author. Tel.: +1 3065854794.

E-mail addresses: bill.bonner@uregina.ca (B. Bonner), m.chiasson@lancs.ac.uk (M. Chiasson), agopal@ivey.uwo.ca (A. Gopal).
} 
(Schoeman, 1984). This interest is also reflected in business studies, especially marketing with its focus on relationship marketing (Cespedes \& Smith, 1993; Fournier, Dobscha, \& Mick, 1998; Foxman \& Kilcoyne, 1993; Bloom, Milne, \& Adler, 1994).

The field of MIS has a particular interest in privacy, information privacy, as designers of systems and custodians of data. The often cited reference point for information privacy research is Mason's identification of four key ethical issues facing the field - privacy, accuracy, property, and accessibility (Mason, 1986). He argues that "We [in the MIS community] must assume some responsibility for the social contract that emerges from the systems that we design and develop" (Mason, 1986, p. 11). Since then many MIS scholars have engaged in information privacy research (Clarke, 1988; Culnan, 1993; Laudon, 1986; Stewart \& Segars, 2002, to name only a few).

An important theme of this research is the metaphor of balance, invoked either through explicit appeal (Culnan \& Armstrong, 1999; Culnan \& Bries, 2003) or through implication in the suggestion of tradeoffs between individual information privacy and other goals (Smith, 1993). The appeal to this metaphor is reflected in practice as well, as organizations explicitly refer to the goal of striking a balance either in policies (Royal Bank of Canada, 2007) or literature (Equifax Canada, 1993; Canadian Standards Association, 2008). Indeed the Royal Bank of Canada privacy policy states that Canadian private sector privacy legislation is "essentially about balance". This ties in to the core issue identified by the Organization for Economic Cooperation and Development (OECD) in creating fair information principles, "The need of balancing competing interests of privacy on the one hand and freedom of information on the other" (Organization for Economic Co-Operation and Development, 1980, p. 16.)

The appeal to balance and the implied employment of a scale makes intuitive sense. Privacy is one right among many and legitimate tradeoffs can and must be made in the interests of society. Nonetheless, the appeal to the balance metaphor is not without its critics. These critiques focus specifically on the enactment of balance, how it plays out in practice, and point to either imbalances of information between individuals and organizations (Foxman \& Kilcoyne, 1993; Shapiro, 1998) or imbalances in power relationships (Clarke, 1988, 1999), both imbalances that work in favour of the interests of organizations. The arguments suggest that pre-existing imbalances shape real enactments of balance on questions of information privacy.

Our historical investigation, sparked by the puzzling outcome of a local enactment of balance, looks critically at how an appeal is made to the discourse and metaphor of balance and the employment of scales, by examining and shedding light on an actual enactment of balance in practice. Using ActorNetwork Theory (ANT) we investigate this specific enactment by 'following the data', a critical but rarely examined element in academic information privacy research, tracing the travels of specific personal data over almost eight decades.

Our findings raise two challenges to the metaphor of balance through making it clear that balance has no specific meaning except in its enactment. First, our findings reveal that actual enactments of balance for organizations are conducted by local actor-networks within the organization, rather than by the organization as a whole. At this local level of enactment we find a surprising lack of knowledge about what is done with personal information, which raises questions about the veracity and credibility of statements and assurances offered by organizational spokespersons. In effect, who is speaking and what do they actually know? Second, we find that data, far from being an artifact or passive object, is the catalyst that draws others to form associations with and around it and the threads that connect these associations can extend in surprising directions, unknown to the organizations supplying the data and certainly the individuals supplying personal data.

The structure of the rest of our paper is as follows. The next section sets up the specific case and research questions followed by the theoretical lens and method employed. This is followed by the research findings, discussion and conclusions.

\section{Setting and research question}

We were aware of the dominance of the metaphor of balance in issues involving privacy and the peculiar outcome of a local enactment of balance attracted our attention. The enactment stemmed from a privacy audit conducted by the Office of the Information and Privacy Commissioner (OIPC) 
Table 1

Unresolved privacy audit recommendations.

Establish controls over the collection and use of MVR information

Use fair information principles (FIP) to govern the collection and use of MVR data

Conduct audits on uses made of MVR data

Strengthen controls over the issuance of search accounts granting access to MVR data

Limit the release of drivers' abstracts to that permitted by legislation

and the Auditor General of Alberta on the department responsible for the provincial Motor Vehicle Registry (MVR). The audit was requested by the government on the basis that,

"The disclosure of this information [personal information in data banks], and... ensuring adequate privacy practices are adopted - especially as they relate to the FOIP [the provincial Freedom of Information and Privacy Protection] Act - is important to us" (Office of the Information and the Auditor General of Alberta, 1998, p. 3).

The MVR contains the names, addresses, gender, weight, birth date, and hair and eye color of vehicle owners in Alberta, as well as details about the owner's registered vehicle. The privacy audit, conducted in 1996-1997, produced 12 recommendations related to privacy. Seven recommendations were accepted and acted upon by those responsible for the MVR, while five were accepted in principle but action was deferred. The unresolved audit recommendations (Table 1) focused on the lack of control over the collection and use of MVR information, the advisability of applying fair information principles (FIP) to govern the collection and use of MVR data in light of the partial exclusion of the MVR from the privacy act (FOIP), ${ }^{1}$ the absence of audits by the government on uses made of the information, weak controls over the issuance of search accounts granting access to MVR data, and the release of drivers' abstracts in circumstances not permitted by legislation (Office of the Information and Privacy Commissioner and the Auditor General of Alberta, 1998).

These unresolved recommendations were still outstanding two years later when a Legislative Committee of the government of Alberta issued a final report, after conducting a mandatory review of the entire FOIP Act. The final report recommended no change to current MVR practices citing, "historical purposes and practices" as justification (Select Special Freedom of Information, 1999, p. 32).

Given that the government requested the audit because of concern about privacy, we were surprised and unable to explain how this concern was trumped by "historical purposes and practices". Indeed, we reviewed the 700 pages of the minutes of and submissions to the committee and were even more puzzled. There was little reference in these documents to history generally and absolutely no substantiation of historical purposes and practices. We had to conclude that, at least on the surface, something unknown had somehow trumped privacy in this local enactment of balance.

This led to the development of our research question, starting with a more general one. "Why did the scale employed in the enactment of balance tip away from the side representing privacy (important to the government) in favor of the side representing the continued personal data sharing, when there appeared to be little or no substance to the arguments placed on that side of the scale ("historical purposes and practices")? This led to the more specific question: "What is the actual constitution of "historical purposes and practices", that tilted the scale so decisively?"

\section{Theoretical lens and method}

Philosophical principles of Actor-Network Theory (ANT) informed the development of the research question, particularly the work of Latour with his focus on ontology; the creation of and sustenance of a particular reality (Latour, 1992). In this instance, the practice of selling MVR data was sustained by the Legislative Committee that acted as a spokesperson (Latour, 1988) for what appeared to be a black box (Latour, 1987), a sealed box of unknown substance with the label "historical purposes and

\footnotetext{
${ }^{1}$ The FOIP Act exempts uses made of records contained in the Office of the Motor Vehicle Registrar (Statutes of Alberta, 1994, Chapter F-18.5, Section $4(1)(\mathrm{h}))$.
} 
practices". Our interest, taking the concept of balance seriously, was to probe for the substance of the argument placed opposite privacy in this enactment of balance.

Our lack of knowledge about what to expect led to the adoption of ANT as our lens for this research. "...ANT does not tell anyone the shape that is to be drawn - circles or cubes or lines - but only how to go about systematically recording the world-building abilities of the sites to be documented and registered" (Latour, 1999a, p. 21). Each research subject has within it all that is needed to understand its development. With this in mind we followed the key underlying methodological approach of ANT that "'follow[ing] the agents around' has priority over everything" (Latour, 1999b, p. 128). An agent is something or someone who either acts, forces others to act or can be enlisted into action (Latour, 1993). ${ }^{2}$ As "Nothing becomes real to the point of not needing a network in which to upkeep its existence" (Latour, 1991, p. 118), we needed to answer the "How?" question; how was this practice sustained?

ANT is a constructivist philosophy positing that all action is local and is taken for local reasons. It is only through alignment with others that something larger and more pervasive appears (networks, linked local actor-networks). Others enlist in a program and form networks only if they see their interests realized in the alignment. Thus, a successful alignment is one that has permitted drift and translations around an idea so that different local actor-networks see their interests met through taking action. Holmstrom and Stalder (2001) document the consequence of a retail information system sponsor's failure to accommodate critical user interests into the technology. Potential system advocates, not seeing their interests realized in the technology, refused to align around the technology and it was eventually withdrawn.

Other critical Latourian features employed include immutable mobiles (Latour, 1990), avoiding the insertion of divides (Latour, 1987) and a genealogical view of history (Latour, 1992). Immutable mobiles are techniques for capturing data about distant events or things in such a way that captured data can travel to distant centres without the need for the object itself. Paper records and data captured digitally are examples; both enable the faithful transport of data over distance. Divides in the Latourian sense are insertions in continuities that make the subject appear mysterious and without origins. These include time divides (the information age as completely different from preceding times), micromacro divides as separate events rather than a change in the size and scale of interacting local actornetworks, and human non-human divides that artificially separate actants into distinct and separate units, ignoring how each defines the other in interaction. Finally, to understand the present we must trace the path(s) actually taken from the past to the present rather than introduce assumptions about the linear nature of history, a bias we might introduce by starting in the present and looking to the past to understand present day thinking.

\subsection{Data gathering and analysis}

Competition or controversy is important for identifying which actants to follow. When there is an active contest, actants and their networks advocating for competing agendas are visible (Latour, 1987; Scott \& Wagner, 2003). Their words, actions and relationships can be observed and traced. The audit represented a moment of controversy, privacy versus the status quo. The controversy appeared to close with the black box "historical purposes and practices". During the course of our research we came across a number of controversies around MVR data, and these controversies were instructive for revealing what was oftentimes hidden and out of sight.

The goal of ANT research is to describe the process through which diverse actor-networks came to produce and sustain ontology. "In order to make a diagnosis or a decision about the absurdity, the danger, the amorality, or the unrealism of an innovation, one must first describe the network" (Latour, 1991, p. 130). To do this we first immersed ourselves in the immediate controversy around the privacy audit.

After conducting 6 interviews with audit participants and gathering and analyzing related documents, we realized that the research site was going to explode into webs of actor-networks. Initially

\footnotetext{
${ }^{2}$ Latour uses the term agent here but more normally employs the term actor or actant; the latter term to avoid the human only implications of the word actor. We use the expression actor-network here to stress nothing exists by itself, it exists and comes to be defined in interactions or through relations with other things.
} 
we followed all threads due to inexperience with ANT but also because we felt the need to understand the relevant fields of networks around the MVR data. Over time it became apparent that the critical actant on which we needed to focus was the data itself, in particular moments of controversy around the data as this is when actor-networks are rendered visible. In the initial process of developing an understanding of the privacy audit outcome we encountered sketchy references to an earlier controversy over the data. Over the next two years, we traced and fleshed out that controversy and, through tracing identified actor-networks, discovered four less visible controversies. For each controversy we immersed ourselves, searching for and gathering data and conducting interviews where possible for recollections and the identification of any other possible data sources on the particular controversy. Essential questions asked of each controversy were,

(a) What triggered the controversy?

(b) What actor-networks are active and identifiable in the controversy?

(c) What actor-networks are invoked or spoken for in the controversy?

(d) What are the cited motivations for actor-networks, visible or spoken for?

(e) What actor-networks are new in this controversy and what ones have been present before?

(f) How was this particular controversy resolved, if it was?

(g) What is the relationship between this controversy and prior and future controversies?

As we became immersed in the various controversies we came to appreciate the similarities and differences between the controversies and came to realize that the outcome of the privacy audit represented the culmination of a history marked by periodic shocks that had abruptly altered the trajectory of subsequent events. In other words, we came to realize that we could not explain the present by looking into the past but rather needed to explain the present by articulating the past embedded in it. ${ }^{3}$ In reflexively attempting to articulate our understanding and describe each episode and their relationships we identified gaps in our understanding and sought out and gathered additional information. In the latter stages, analysis, understanding and describing through writing were intertwined and iterative.

\subsection{Data sources}

The findings reported are based on interviews, analysis of interview transcripts and gathered documents. In total 16 in-person interviews were conducted in Alberta generating $12 \mathrm{~h}$ of recordings that were subsequently transcribed. Seventeen telephone interviews were also conducted (some of them were follow-ups on earlier in-person interviews) and notes on the conversations were taken. Extensive use was made of email and written correspondence for individuals or organizations outside Alberta, where the events took place.

Table 2 lists the most significant interviews (all conducted on the condition of anonymity). These interviews included individuals involved in the privacy audit, a member of the FOIP Review Committee (multiple times), current employees involved with the MVR, former government cabinet ministers and former employees of the Alberta and Manitoba Motor Vehicle Branch (responsible for the MVR). Phone interviews were also conducted with individuals knowledgeable about the firms buying MVR data. ${ }^{4}$ Interviews were used primarily as sources of information about key actants and events in order to then identify and gather documents. Interviews were never used as the primary source of information due to the potential for biased recall of information. This potential was evident in a number of interviews.

Table 3 lists the key documents gathered and analyzed in the course of this research. The starting point was the minutes of the meetings of the FOIP Review Committee and the Privacy Audit report. An early interview revealed the existence and location of an unpublished history of the Motor Vehicle Branch and the author. Other provincial privacy acts that formed the basis of the Alberta Freedom of Information and Protection of Privacy Act were also gathered and analyzed. Over $300 \mathrm{~h}$ were spent in the Alberta provincial archives examining records dating back to the early 1900s. That search

\footnotetext{
${ }^{3}$ This is a genealogical non-linear view of history that Latour shares with Foucault and Nietzsche (Latour, 1993).

${ }^{4}$ Our guarantees of anonymity mean that we have to be somewhat vague on the details.
} 
Table 2

Significant interviews.

\begin{tabular}{ll}
\hline Interviews & Members of the privacy 1996-1997 audit team and Alberta Registries ${ }^{\mathrm{a}}$ \\
& Member of the FOIP Review Committee (multiple times) \\
& Current employees of Alberta Registries (responsible for the MVR) \\
& Former Alberta government cabinet ministers (1950s-1990) \\
& Ten former employees of the Alberta Motor Vehicle Branch (1941-1999) \\
& Two former employees of the Manitoba Motor Vehicle Branch (1940s-1970s) \\
& Key retired individuals familiar with organizations buying MVR
\end{tabular}

a Alberta Registries is an umbrella organization for a number of provincial registries, including the MVR.

Table 3

Significant source documents.

\begin{tabular}{ll}
\hline Key documents & Sevzen hundred pages of the minutes of the FOIP Review Committee, 1996-1997 \\
Privacy Audit report, 1997 \\
Unpublished history of the Motor Vehicle Branch, 1906-1960 \\
Privacy acts of Ontario, British Columbia, Alberta and Saskatchewan \\
Internal Ministerial and department records, the Alberta Provincial Archives including (a) correspondence \\
with Polk (1960s-1970s), (b) correspondence around sale of MVR data (1960s-1980s), (c) a partially \\
completed legal research project on the sale of MVR data (1979) \\
Alberta Government Hansards 1960-2000 (official record of statements made in the Alberta Legislature) \\
Legislation governing the MVR, 1906-2000 \\
Documents from the Saskatchewan Provincial Archives \\
Companies Office Manitoba, provincial company registry \\
A report to the Alberta Legislature of the Special Select Committee on Invasion of Privacy, 1969
\end{tabular}

produced a series of documents around the bulk sale of MVR data to R.L. Polk (Polk) of Canada Limited. Over $50 \mathrm{~h}$ were spent researching and analyzing Government Hansards (detailed records of government deliberations in the Legislature) and an equal amount of time was involved in tracing the evolution of MVR legislation from 1906 to 2000. A later search in the Saskatchewan Provincial Archives uncovered evidence of the sale of MVR data as early as in 1926 to Wiggins Systems Limited (Wiggins) and a 1951 mailing list produced by the same company. A document acquired from the Companies Office in Manitoba revealed Wiggins' bankruptcy in 1958 and the reasons for it. Finally interviews revealed a controversy around the sale of MVR data in 1969 leading to a report prepared for the government of Alberta.

In what follows, we present the findings forward in time in five general streams. First, we identify and briefly discuss a somewhat patchy history from 1906 to the late 1950s that includes technologies no longer used. Second, we reveal evidence of concern in the early 1960s, within the government, around the legality of the sale of MVR data and rising privacy concerns. This period also sees the introduction of a new actant, the modern computer. Third, in 1972, a full blown controversy emerges revealing a wealth of information about actor-networks around MVR data. Fourth, almost immediately after the crisis a key actants attempts to narrowly interpret restrictions resulting from the 1972 crisis, threatening to reignite the controversy. Finally, we see continued but subdued threads of concern about the sale of MVR data through the 1970s into the 1980s that later appeared in the privacy audit of 1996-1997.

In presenting our findings in terms of distinct episodes related to controversies we realize that we are arbitrarily dividing time. This is for presentation purposes only. Some tensions underlying each controversy pre-date and continue through each controversy. We also acknowledge the difficulty, as does McGrath (2002), of condensing a wealth of information within the constrained space of a journal article.

\section{Findings}

Our findings are presented as episodes, identified in Table 4, evolving around a key controversy titled All Access to MVR Data Ceases. From this controversy, identified actants and networks were 
Table 4

Organization of findings.

\begin{tabular}{ll}
\hline Controversy & Years \\
\hline Under the Radar (no controversies identified) & $1926-1960$ \\
Legality and Rising Privacy Concerns (the computer is enrolled) & $1960-1971$ \\
All Access to MVR Data Ceases & 1972 \\
Attempted Function Creep & 1973 \\
Uncontrolled Growth (computer access accounts, privacy and liability concerns) & $1974-1980$ \\
\hline
\end{tabular}

traced backward to the periods labeled Legality and Rising Privacy Concerns and Under the Radar, and forward to Attempted Function Creep and Uncontrolled Growth, leading to the Privacy Audit of 19961997.

\subsection{Under the radar (no controversies identified)}

Sometime before 1941, two key pieces of technology were employed in the motor vehicle registration process: the Graphotype and Addressograph machines. These machines together produced seven copies of the motor vehicle registration that included detailed information about the vehicle and its owner. The seventh copy, known as the "wiggins" form was batched and periodically mailed to a company in Winnipeg Manitoba, Wiggins Systems Limited (Hogg, 1985). Archival evidence indicates that Wiggins paid three-quarter of a cent for each registration in 1928 (Department of the Provincial Secretary, 1928). The actor-network constituting the registration process continued to provide Wiggins with this information until it filed for bankruptcy in 1958. According to the trustee, the bankruptcy was caused by a loss of cash flow, "Primarily caused by the loss of volume due to the automotive trades taking their direct mailing contract from him [Charles S. Wiggins] to an agency operating in Eastern Canada" (Canadian Credit Men's Trust Association Limited, 1958).

Little is known of Wiggins, but a three-inch thick document dated 1951 was discovered entitled, "Wiggins Systems Limited Mailing List", with the sub-heading, "Make Good use of your Mailing Lists, It will Push Up your Sales" (Wiggins Systems Limited, 1951, italics in the original). The document lists all registered vehicles in Regina, Saskatchewan and is organized around the vehicle license number providing the vehicle owner's name, address, and vehicle serial number, make and style. As Regina is a relatively small city, it is reasonable to assume that lists were produced for other Western Canadian cities as well. As hundreds of thousands of copies of registration forms were sent to Wiggins, we can only imagine the scale and scope of the actor-networks associated with Wiggins that were involved in the manual labour of sorting, organizing and producing lists, as well as those involved in actually buying the lists. The technologies employed in registering motor vehicles continued to be embedded in the MVR process until the 1960s (the process was computerized in 1962 in Alberta) and the paper based release of MVR data continued after Wiggins, although it was now released to a different actor-network, the R.L. Polk Company of Canada.

Very little is known about this period or the rationale of the "wiggins" form. The described method of registering motor vehicles was a practice inherited by employees who started in the early 1940s and extensive searches through department and ministerial files in the provincial archives of Alberta and Saskatchewan reveal no additional information; the practice did not appear to be on anyone's radar. What carries forward from this period is the sale of MVR data, the technology embedded in the actor-network registering vehicles, and the "wiggins" form. What is different in the next period is the emergence of the issue in ministerial records, the start of actor-networks coalescing around privacy and the introduction of the modern computer.

\subsection{Legality and Rising Privacy Concerns (the computer is enrolled)}

The bankruptcy of Wiggins, the continued production of the "wiggins" form, and the appearance of Polk appear to have drawn the attention of more senior government officials, within the Ministry of Highways, to a practice that had already been in operation for over thirty years. Correspondence re- 
veals uncertainty within this actor-network about the origins of the practice and concern about the absence of legislative authority to sell MVR data, ${ }^{5}$ in a period of increased concerns about privacy generally.

Throughout the early 1960s senior officials within his department advised the Minister of Highways, Gordon Taylor, to change the legislation to legitimate the sale of MVR data. This was never done, but in 1962 the Taylor actor-network changed the regulations to the Motor Vehicle Act (the legislation governing the MVR), which were expanded to authorize, for the first time, the "bulk" sale of MVR data, identifying Polk as the sole recipient. ${ }^{6}$

The motivations of this actor-network to advise or to take actions which supported the continued dissemination MVR data, with Polk at the centre, is unclear. ${ }^{7}$ In addition to this general inclination, it would appear that the central actant, Taylor, had an issue with Polk having an unfair market advantage as the sole recipient of the data. This was borne out in an interview with him in 2001 and reflected in notes he created for his files.

"With the use of a magnetic tape and the computer, it was possible to make the information available to anyone. The price is 1 cent for each registration if the purchaser supplies the magnetic tape plus $\$ 900$ for the microfilm of new registrations" (Taylor, 1968).

Uncertainty around the practice is evident in internal correspondence. In 1967, Taylor surveyed other provinces about their use of MVR data. Response indicated that all provincial actor-networks sold MVR data to Polk, with two provinces (Manitoba and Quebec that had also computerized the registration process) considering the sale of the MVR data to a national direct marketing company in Montreal, O.E. McIntyre. Taylor also requested information from Polk about its use of MVR information. The response indicated that the information was used primarily by the automobile industry to help an associated network of manufacturers and suppliers plan production and locate new dealerships. The letter focused on the use of MVR data for the War Amputees Association of Canada Key Tag program ${ }^{8}$ and assisting General Motors in a vehicle recall involving all 1965 Chevrolets and Pontiacs (Heil, 1968). The use of MVR data for direct marketing was acknowledged for automotive manufacturers and " $[\mathrm{m}]$ ajor oil companies, tire manufacturers and other companies that more or less are allied with the automotive industry", but the spokesperson indicated that this was a minor part of Polk's business.

Taylor did pursue the possibility of making "the information available to anyone". His staff, under his direction, entered into and completed negotiations on the sale of MVR data on computer tapes to McIntyre (to start in 1968). In preparation, this actor-network again changed the regulations to the Motor Vehicle Administration Act, replacing all specific references to Polk with the general statement that the Minister "may supply registration data in bulk form". 9

As these events took place there is evidence of increased concerns about privacy reflected in a letters from citizens and a government study undertaken in 1969 on privacy (Simpson et al., 1970). Letters from individuals objecting to the sale of MVR data were found in the Alberta Archives collection. Responses from Taylor's actor-network, however, clearly supported the sale of this information and used Polk's statements about the benefits to the automobile industry as justification. This is reflected in the following sample response to such letters.

"While it is true that under the provisions of the regulations this information may be sold to listing companies, it should be pointed out that this does not necessarily support the assumption made by the writer of the article that the sale of such information is the cause of your receiving advertising material in the mail. Because similar articles have been published in the past, we made some inves-

\footnotetext{
${ }^{5}$ All motor vehicle legislation and related regulations were reviewed, from 1905 to 1962, and the sale of MVR data does not ever appear to have been explicitly authorized.

${ }^{6}$ Alberta Regulation 417/62.

7 Polk paid $\$ 7637.47$ for MVR data in 1967, a relatively small number, making it hard to argue that the motives were entirely

8 The War Amputees Key Tag program, using MVR data, mailed every registered vehicle owner a key ring tag. If keys were found they could be placed in any mailbox where they would be sent to the War Amputees who would mail them to the owner. Key tag recipients were invited to make a donation for these key tags.

9 Alberta Regulation 453/67.
} 
tigation in regard to the manner in which the information is being used and have been assured that the main user of this information is the motor vehicle industry which, in many cases, has been instrumental in helping rather than hindering the users of motor vehicles" (Taylor, 1969). ${ }^{10}$

Unable to prove that MVR data was used for direct marketing and up against actants aligned with Polk and the automobile industry, individuals questioning the practice were on their own. In these letters, though, we see the initial formation of actor-networks around the concept of privacy. At this point these networks were relatively weak in the face of significant others, such as the Taylor actor-network.

However, the significant change of trajectory towards the increased use of MVR data for direct marketing purposes did not materialize. McIntyre, speaking for its actual and potential network, made a fateful decision in deciding to defer enacting the contract until all other provinces were able to provide computer tapes, something that did not happen for another six years. Instead, two years later the government changed and a new actant in the form of a new Minister of Highways with a different orientation took over responsibility for the MVR.

\subsection{All Access to MVR Data Ceases}

In 1971 Taylor's party lost the election and new Minister of Highways, Clarence Copithorne, introduced a different orientation into the mix. Copithorne had been a member of the legislative committee studying privacy only two years earlier and it appears that privacy was important to him (Simpson et al., 1970). According to an interviewee, it was Polk's practice to monitor changes in critical provincial actor-networks and to arrange to meet with them and keep the Polk actor-network functioning. The change in government in Alberta and Copithorne's quick reaction to the following event happened before this meeting could occur.

Copithorne received, from another cabinet minister, copies of four letters mailed to government employees from Laurier Life Insurance (Hohol, 1972). The address labels attached to these letters included the make and age of the employee's vehicle, the gender of the employee and other unidentifiable pieces of data (Exhibit 1). The source of the information was clear and within four days Copithorne made the following announcement in the Alberta Legislature.

"Mr. Speaker, in the past, information regarding those who have bought license plates in the Province of Alberta has been made available for a fee to commercial companies, which has contributed to the invasion of privacy through mail. Mr. Speaker, I wish to announce that commencing with this year's registration, data in bulk form will no longer be supplied, either to individuals or firms" (Alberta Hansard, 1972).

The actions of Copithorne'a actor-network destabilized Polk's network, exposing Polk's vulnerability as the network spokesperson. Copithorne refused Polk's initial lobbying efforts to restart the flow of MVR data, demanding detailed information about Polk's use of MVR data. The response indicates that, in 1971, Polk had sent almost two million mailings on behalf of its network to Alberta residents, listed in Table 5 (Heil, 1972).

An extended but largely invisible network of organizations had evolved around the use of this very accurate data (updated by motorists at least annually ${ }^{11}$ ). Polk itself had previously been invisible in these mailings as, like credit bureaus today, Polk produced the mailings using letters and envelopes supplied by these organizations. Polk's name never appeared in the mailings.

Pressure to restart the flow of information to Polk came from a number of actor-networks aligned around Polk's access to MVR data. These include the War Amps who relied on Polk's computers to prepare mailing lists for its Key Tag program, the Motor Vehicle Manufacturers Association, Cummins Diesel Power Ltd. and a magazine publisher. These actants were not necessarily speaking in support of Polk though, as is evident in the following quote. Cummins Diesel indicated that it was willing to

\footnotetext{
10 These letters were written in response to newspaper articles or personal experience. This representative response cites most of the justifications used by the government in responding to letters of objection.

11 More often if vehicle owners move, they must report address changes within 90 days or face fines.
} 


\author{
MEMORANDUM DEPARTMENT OF LABOUR \\ FROM: $\quad$ Dr. A.E. Hohol, Minister of Labour \\ To: $\quad$ Hon. C. Copithorne, Minister of Highways and Transport \\ DATE: $\quad$ March 22, 1972 \\ RE: Low-Cost, Cash Value Life Insurance \\ The attached memorandum from my Deputy, along with copies of \\ envelopes received from Laurier Life Insurance, appear to be self- \\ explanatory. I might mention that the envelopes indicate names of people \\ on the staff of my Department.
}

Envelope mailing labels

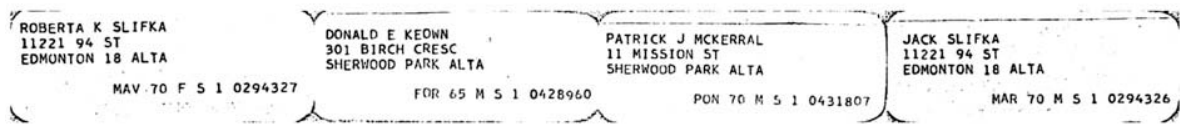

Exhibit 1. MVR data appearing on mailing labels.

Table 5

Distribution - mailings made by Polk into Alberta, 1971.

\begin{tabular}{llll}
\hline Automobile recalls & 83,737 & MacLean Hunter & 4,215 \\
War Amputees & 494,822 & Ogilvy and Mather (American Express) & 50,000 \\
Foster Advertising, Toronto & 288,902 & Simpsons Sears & 21,500 \\
MacLaren Advertising, Toronto & 362,799 & Sovereign Seat Covers, Ontario & 188,650 \\
Postal Promotions, Toronto & 32,964 & Automobile Dealers - general & 141,275 \\
National Consumer Marketing & 20,000 & Oil and Gas Companies & 143,200 \\
Readers' Digest & 12,400 & Others & 69,856 \\
Mil Mac Publication & 1737 & Total & $1,916,057$ \\
\hline
\end{tabular}

abandon Polk if it could receive the data directly from the government, underscoring the precarious position of spokespersons.

"We are not aware nor are we interested in circumstances surrounding your decision with R.L. Polk however if your decision is firm we would like to arrange to obtain from you registration information so that we may process it" (Koziak, 1972).

Eight months after cutting off access to MVR data, Copithorne advised his staff to begin negotiating a new contract with Polk. While the flow of bulk MVR data was restarted, the subsequent contract contained clauses limiting the use of personal data for statistical and vehicle recall purposes only. It is unclear whether this was the event that sparked similar actions by other provincial actor-networks, or whether it would have happened anyway given a growing increase in those willing to align around privacy, but over the next few years, other provincial actor-networks imposed similar restrictions on the Polk actor-network.

Unfortunately Copithorne died in the late 1970s and his records in the archives are limited. A number of interviewees offered anecdotal evidence that indicate that pressure was applied to resolve the issue in favour of Polk. This included distant federal Members of Parliament (in Ontario), aligned with automobile manufacturing networks located in their ridings. Significant pressure also emerged from politicians, individuals and newspaper editorials aligning in favour of the War Amputee's program. This is an example of actants acting locally for local reasons. None of these actants was involved in 
or had knowledge of Polk and the other actants networked around the dissemination and use of this data and yet their actions, for different reasons, had the effect of supporting the Polk actor-network.

\subsection{Attempted Function Creep}

Within one year, though, Polk risked reigniting the controversy in seeking Copithorne's approval to issue a comprehensive survey to new car buyers in Alberta, on behalf of one of its network members, the Ford Motor Company Limited.

"It is the term "market research analysis" [limiting phrase in Polk's new contract with Alberta] which we question since, in our terminology, this includes surveys of car buyers and owners in order to determine preferences and other information of value to the manufacturers in their future planning. These have been carried on for many years and we continue to do such market research studies in other provinces" (Heil, 1973).

The new contract contained a clause that motor vehicle manufacturers were not to get the names of registered owners of vehicles. The survey, attached to Heil's letter, was to be sent to all new car buyers in Alberta, not just Ford buyers. The multi-paged survey asked questions about the vehicle purchased, factors that affected the purchase decision and the dealer experience. It concluded with personal questions about how the car was paid for, other cars owned in the household, and questions about the buyer's gender, age, marital status, the number of children living in the household, the last grade of school completed by the buyer, the family's income, the buyer's occupation and name and address.

This attempt to narrowly interpret restrictions recently placed on the use of this personal information was met with a blunt response.

"Mr. Heil, I must admit I am somewhat surprised at your latest request, especially in view of the fact that the use you now propose for the statistical data we provide is exactly the same use which prompted the discontinuation of our previous agreement" (Copithorne, 1972).

Thus, while Polk did regain access to Alberta MVR data, Polk's attempt to reestablish its role as a central actant-network in national direct marketing and market research networks failed with the enforcement of the restrictions. Unlike the actor-network involving Wiggins that collapsed abruptly with its bankruptcy in 1958, Polk's centrality as an actant in the use and dissemination of gradually diminished from 1972 onward, as others provinces enacted similar restrictions.

\subsection{Uncontrolled Growth (computer access accounts)}

While the direct marketing aspect of actor-networks around MVR data never materialized in the case of McIntyre and faded away over time with Polk, changes in computer and communications technology enabled other possibilities that were acted upon, with the modern computer being enlisted in actor-networks in new ways. The digital capture of data on magnetic tapes had earlier created the possibility of capturing the data once and selling it repeatedly, enabling the earlier deal with McIntyre. Over a relatively short period of time databases and improvements in telecommunication technology enabled something different, and actions were taken. Local actor-networks within government created search accounts for ministry approved outsiders to access MVR data for a fee. The gravitation of actants towards MVR data available this way got out of hand very quickly.

According to a government study in the late 1970s, "Officials of the department have spied defects in the practice of imparting information to whomever requests it merely upon payment of the fee" (Solicitor General's Department, 1979, p. 4). The "spied defects" included a lack of legislative authority for selling the information, vague grounds for initially establishing an account, a lack of audit trails on subsequent searches and little or no attempt to assess the continued need for particular accounts. The report indicated that there were approximately 1000 search account holders in 1979. The largest account holders included bank branches, finance companies, collection agencies, insurance companies, car dealerships, private investigation companies, department stores, a tracing company, a major grocery store chain and others. According to the report, 
"It is this kind of recipient [search accounts] that most troubles those officials in the MVD [Motor Vehicle Division] who are sensitive to the security issues suggested by the wide disclosure of personal data" (Solicitor General's Department, 1979, p. 5).

Correspondence within the Solicitor General's Department, which had become responsible for the MVR since 1975, indicate that the range of concerns included privacy issues, concerns about the type and amount of information released, liability issues around the use of the data to find the addresses of women, and the propriety of releasing any information.

From departmental documents and the government study a recurring theme of internal uncertainty about the propriety of selling MVR data seemed to exist. However, policy changes attempting to limit access to MVR data tended to be ad-hoc and inconsistently enforced.

"As will be repeated throughout this study, this change in policy [limiting access to individuals] reflects a doubt within the MVD about whether this traditional service is a proper function of the Division at all" (Solicitor General's Department, 1979, p. 10).

From this point on no further documentary threads suggesting the existence of a controversy around the dissemination of MVR data are evident. The fact that less than twenty years later the government requested the privacy audit, out of concern for ensuring that "adequate privacy practices are adopted" (Office of the Information and Privacy Commissioner and the Auditor General of Alberta, 1998, p. 3), suggests that concerns around the dissemination of MVR data had not disappeared.

\section{Discussion}

\subsection{Constitution of "historical purposes and practices"}

Our ANT analysis of the constitution of the black box, "historical purposes and practices", reveals an absence of purpose. Rather than finding some underlying continuity of identifiable purposeful action we instead found a series of actions taken by local actor-networks within government that have altered, sometimes sharply, the shape and scale of interconnected actor-networks that have gravitated to and aligned around MVR data over the course of the last 80 years. There has been no continuous purpose.

There have as well been a number of continuities. Firstly, the data has been in action and been integral to the formation of actor-networks for the last 80 years. Secondly, documentary evidence reveals that for at least the last 50 years there have been fairly constant questions about the legitimacy of the practice itself. Finally, the most consistent and overarching constant has been the forgetting of history; each time questions about the practice have arisen, they have appeared as though new and without a past.

Sharp evidence of this forgetting of history is reflected in the concerns raised in the 1979 study that "spied defects" in both the rationale of the practice of releasing this data at all, as well as the lack of control over the process. The forgetting of history is clearly reflected in the remarkable similarity of the "spied defects" in 1979 to the issues raised in the privacy audit of 1997, compared in Table 6. The only substantial difference between the two events is the 1997 recommendation to adopt fair information principles (FIP) as privacy's representative in the enactment of balance; FIP did not exist and were not part of an actor-network in $1979 .{ }^{12}$

\subsection{Explaining the tipping of the scale in favour of "historical purposes and practices"}

That the "historical purposes and practices" argument was successful without revealing its substance, begs questions about the substance of privacy's representative on the other side of the scale. We will only speak to this briefly here as it clear that, since the scales in this enactment of balance

\footnotetext{
12 FIP, developed by the OECD and adopted in Canada were not published until 1980 (Organization for Economic Co-Operation and Development, 1980).
} 
tipped so decisively in favour of an unsubstantiated "historical purposes and practices", privacy's representative possesses little actual substance.

In the request for the audit, the deputy minister appealed to the FOIP actor-network as privacy's representative,

"The disclosure of this information [personal information in data banks], and...ensuring adequate privacy practices are adopted - especially as they relate to the FOIP [Freedom of Information and Privacy Protection] Act - is important to us" (Office of the Information and Privacy Commissioner and the Auditor General of Alberta, 1998, p. 3).

The privacy sections of Canadian FOIP acts are based on fair information principles (FIP) developed by the OECD (Office of the Information and Privacy Commissioner, 1999, p. 1). The substance of these principles and their enactment in Canadian legislation has been discussed in depth elsewhere (Bonner \& Chiasson, 2005), however, a couple of points are worth noting. Firstly, FIP were developed largely by actor-networks with a vested interest in ensuring the mobility of data. FIP are not privacy principles but rules about data that, once met, permit the movement of data. FIP have become a black box embedded in many actor-networks where they are privacy's unquestioned representative. Secondly, Canadian public sector privacy legislation (Freedom of Information and Protection of Privacy legislation) is integrated with access to government information legislation. Under the access to information side of the legislation, Canadians can access general information possessed by the government as well as any information the government has about them (with some exceptions to both) at no cost.

In practice every provincial actor-network act exempts the use of MVR data from FOIP legislation. From interviews in Alberta, the reason cited most often for this exemption is that if the provincial MVR was included under FOIP legislation, individuals could request their driver's abstract under the access to information side of the legislation, for instance, and bypass the fee system in place. Legislative actor-networks have decided that it is easier to exempt these agencies from FOIP altogether. Thus, the actual substance of privacy's representative (FOIP) and its potential for restrictions on access to MVR in this enactment of balance was decided in a series of earlier balancing acts involving actor-networks (FIP and then FOIP), that limited, in the first instance, the definition of privacy, thereby ensuring its mobility and, in the second instance, created an outright exemption of MVR data from the scope of the legislation.

Based on our findings we have to conclude that the success of the appeal to unarticulated history rests on a limited conception of privacy embedded in the FIP-FOIP actor-networks and failure on the part of other actor-networks (legislative and media for instance) to probe for the substance of historical purposes and practices, granting it a substance that it does not possess. We cannot say if there were undiscovered and undocumented behind the scene actor-networks acting to maintain the status quo, but we can say that if balance is a useful and meaningful metaphor then its enactment must be transparent and fully examinable and examined.

\subsection{Insights gained and challenges raised through our ANT analysis}

We wish to explore two critical challenges to an appeal to the metaphor of balance, deriving from our extended historical investigation employing the lens of ANT. Firstly, within an organization, where does the enactment of balance take place? This challenge relates to what an 'organization' knows and can actually say about its practices. Secondly, what does an organization and those within it enacting balance know of actor-networks that extend beyond organizational boundaries? This relates to data as an actant in the creation of actor-networks that gravitate towards and network around personal data once it is made available.

\subsubsection{Locus of decision-making in enactments of balance}

Our findings support those identified in the literature that argue the existence of an imbalance of power or information between organizations and individuals, in favour of organizations. Individuals have been largely absent in enactments of balance and in many instances been unaware of the very existence of the practice itself. The challenge our investigation raises, though, is about the nature of organizational decision-making and organizational knowledge about uses made of personal 
Table 6

1979 spied defects versus 1997 privacy audit findings.

1979 spied defects (Solicitor General's Department, 1979, p. 4)

A lack of legislative authority for selling the information

Vague grounds for initially establishing an account

A lack of audit trails on subsequent searches Little or no attempt to assess the continued need for particular accounts
1997 findings/unresolved privacy audit recommendations

No evidence of legislative authority or informed consent from the individual to whom the information relates ${ }^{\mathrm{a}}$

Weak controls over the issuance of search accounts granting access to MVR data $^{\mathrm{b}}$

The absence of audits by the government on uses made of the information ${ }^{\mathrm{b}}$ Auditor General Department's discovery of search accounts in its name ${ }^{a}$

The advisability of applying fair information principles (FIP) to govern the collection and use of MVR data in light of the partial exclusion of the MVR from the privacy act (FOIP) ${ }^{\mathrm{b}}$

\footnotetext{
a Reported in privacy audit report.
}

b Unresolved audit recommendations.

information. Specifically, the challenge with respect to the metaphor of balance centers on assumptions about where in organizations enactments of balance occur; who enacts balance and the level of knowledge these actor-networks actually possess.

Our findings make it difficult to view an organization as an entity, but rather a loose collection of actor-networks. 'The government' as such did not make decisions about MVR data in our study, those decisions were made by local actor-networks and we found repeated examples of local actor-network knowledge being weak and rather tenuous. Wiggins and its actor-networks appear to be an historical organizational mystery supported by actor-networks in which the Graphotype and Addressograph technology was embedded. Subsequently, Taylor's actor-networks supported those of Polk but with little real knowledge about what was actually done with the data. The push to expand the use of MVR data for marketing purposes, in signing contracts with McIntyre, was knowledge that only Taylor's actornetwork within the government possessed. Further evidence of the continued lack of organizational knowledge about balancing acts is reflected in the commissioned study in the late 1970s by other actor-networks within the government around search accounts; the weak basis for issuing them, their lack of expiry date and the lack of audits conducted on MVR data uses. This uncertainty around search accounts was evident in the 1970's study and again in the audit findings of the late 1990s. Further, actor-networks involved in the execution of the privacy audit do not appear to have been aware of the same questions having been asked by other government actor-networks within the last 20 years.

There is a more recent example reinforcing our sense of organizations as a collection of loosely aligned actor-networks. An opposition Member of the Legislature (MLA) and a member of the FOIP Review Committee, Pamela Paul, raised questions about the impact of selling MVR data in instances of potentially violent domestic breakups. Registering change of addresses with the MVR is required by law and a reading of the minutes of the meeting suggest she was quite disturbed to find out that anyone with a search account could access new addresses (Alberta Legislature, 1998, p. 10). This elected official and law maker of the same organization that sells MVR data was taken aback by the existence of the practice.

This view of an organization raises questions about the organizational calculus involved in enactments of balance, the necessary counterpart of Culnan and Armstrong's (1999) "privacy calculus", defined as "an assessment [by individuals] that their personal information will be used fairly and they will not suffer negative consequences" (p. 106). This theory suggests that individuals actively calculate and attach weights to the statements of organizational spokespersons (privacy policies, in store statements, public statements, etc.). Yet our study suggests that a focus on the organizational level as a unit of analysis is problematic as 'organizations' do not make decisions; local actor-networks within organizations do. Not only that, but we also saw repeated examples of local actor-networks engaging in a form of calculus for the organizational as a whole, an activity that was not well-informed or consistent over time.

The local nature of the organizational calculus with limited information leading to decision-making and action is cause for concern as this is where acceptable levels of 'substance' and 'justification' are determined and where actual enactments of balance occur. Obviously this does not give all local actor- 
networks within organizations a free pass to proceed with all desired actions as the potential clearly exists that some planned or actual actions taken by local actor-networks can meet with resistance from other actor-networks within an organization. Our study, though, documents 80 years of actions taken with minimal challenge and little demonstrated substantive benefits. This leads us to speculate that, as in the case here, once actions taken have been in place for a while, their continued success and justification may benefit from appeals to history that add substance that they might not otherwise possess.

We have spoken so far about the locus of decision-making within and on behalf of organizations, but the insights provided by the ANT lens and the time period covered by our investigation also raises concerns about organizational knowledge and acknowledgment of actor-networks that form around available data, extending beyond organizational walls.

\subsubsection{Data as an actant in the formation networks}

Our investigation reveals that the actor-networks emerging around the use of personal data are not new. They pre-date the wide adoption of computer technology and certainly the advent of distributed computing and the internet. The challenge arising is how to study or understand issues of privacy without explicitly probing for, acknowledging and incorporating the full life of data beyond its original collection point within organizational walls. Our study reveals that data is not a static artifact, but rather is embedded in and is a catalyst for the formation of many different actor-networks. In this sense data is clearly an actant that has been active in the creation of networks over the last 80 years and whose physical manifestation (paper, digital tapes and then stored in databases) has played a role in creating and dissolving networks. It played a central role in destabilizing the Polk actor-networks with its appearance on mailing labels (Exhibit 1). ANT as a tool for revealing data as an actant in creating and sustaining networks is enlightening but at the same time disturbing, as we are not aware of any studies that have focused on actual networked action around data. The one exception is Smith (1993), although his study focused on actor-networks within specific firms.

For instance, Polk is defined by data, starting with the founder of the company compiling lists of shopkeepers within walking distance of train stations, for travelling salesmen in 1870. By 1968 Polk was generating 60-million dollars a year through its lists (Time Magazine, 1968). Similarly credit bureaus are defined by data, evolving from black list record keepers (lists of people who demonstrated lack of creditworthiness) in the early 1900s to collectors of files on everyone's credit history (Rule et al., 1980).

If a picture is worth a thousand words we would like to invoke the image of a section of land (one square mile) of corn, just before the harvest. From a bird's-eye view the field is an impressive sight, a tall dense forest of leafy green as far as the eye can see. From a ground level view, outside of the cornfield, this same density of nine foot tall corn obscures details of the actual content of the field as, beyond the first ten feet of the edge of the cornfield, details are lost in a sea of green stocks and leaves. What lies beyond is unknown. With this image in mind, our investigation reveals that no actor-network group within the government, including the critical actor-networks enacting local balance, had a bird's-eye view of what was done with MVR data. Thus we situate the data collector actor-network, the within-government actor-networks responsible for the MVR, at the edge of the cornfield accessible to individuals.

Personal data provided to the government at the edge of the field then enters into the cornfield transmitted along network lines to other actor-networks situated in partially cleared pockets within the field. Over the course of the last eight decades transmission of personal data was accomplished with the immutable mobiles of physical paper (the wiggins form), magnetic tapes and finally digital telecommunication lines providing access to databases. The first destination network node in the cornfield is known to at least some actor-networks within the government and has in the past included Wiggins, Polk, and search account holders. Beyond that first level of transmission, knowledge about the actual subsequent travels of the data became very sketchy or even unknown to actor-networks within the government, those collecting data at the edge of the cornfield and those enacting balance within the government.

This is one of the key insights that our ANT investigation affords, insights and revelations into the cornfield itself, by discovering and following the actual actor-networks that have formed around data 
and by tracing the threads that connect. For example, at one time there was a direct thread between Polk and the government and very real threads, unseen by those within government, connecting the government to American Express, Readers Digest Sears, and MacLaren Advertising. The Copithorne actor-network later cut off Polk but did not appear to be aware of the thread connecting the government through Polk to the War Amputees' actor-network. These discovered network linkages are now abandoned, as is the once direct thread to Wiggins and the connections from there to the Wiggins actornetwork. At present there are direct network connections from some government actor-networks to search account holders. Yet the observations of the spied defects around search account holders in 1979, repeated in the 1997 privacy audit findings, regarding the vague basis for establishing search accounts, the lack of audits done and lack of monitoring of the continued need for search accounts, suggest that we are seeing history repeat itself. Where this data goes, beyond the initial threads established by few actor-networks creating search accounts and enacting balance, is uncertain and unknown.

If the government is unaware of distant actor-networks aligned around MVR data, individuals supplying it know even less. A recent telling example of the lack of individual knowledge of networks around personal involves Abacus, as it merged with Doubleclick in late 1999. The reports vary in the details but are consistent in reporting that Abacus held over 2 billion personally identifiable consumer catalog transaction records and that Abacus deals with 1500 retailers (Macavinta, 1999a, 1999b). ${ }^{13}$ Abacus is not an institution that individuals deal with or even know about. Somehow (and it would be interesting to explore) actor-networks have aligned around Abacus, catalog companies and transactional data so that Abacus, way out in the cornfield somewhere has created a market place of anonymous actor-networks around data, unknown to the individuals supplying data to the catalog companies at the edge of the cornfield.

While our findings involving a government agency amplifies our concern about this theme, as governments tend to be the bodies to which individuals turn to protect privacy, it would be a naive simplifying assumption to assume it is any different in the private sector. In ANT terms, accepting this assumption without substantiating it would be tantamount to accepting a black box without being aware of its contents. The existence of organizations and networks made possible by the availability and mobility of data, such as Abacus, Acxiom, credit bureaus and others, leads us to believe that our concerns about a lack of knowledge of extended networks around available personal data are just as likely to exist in the private sector.

\section{Conclusion}

Before offering concluding comments, we must speak to any potential limitations of our research methodology.

First, networks and their interactions are potentially endless and the decision to follow particular threads involves choices based on research interest and researcher understanding. We also found particular empirical threads leading to dead ends, occasionally because data was simply unavailable (for instance the origins of the practice itself) or because of resource limitations (we were restricted to local provincial archives and could not investigate all provinces). Second, we acknowledge that participant viewpoints and archival material can only partially validate our results, given the critical and reflective involvement of the researchers in the study direction, and the potential influences of undocumented events. Third, such studies produce a wealth of threads, data and information and we had to restrict our principal focus in this paper to "historical purposes and practices", limiting our account of FIP on privacy's side of the scale. Our approach of following the data, something we have not seen in MIS privacy research, necessitated we focus our efforts and presentation on that unique aspect of our research and the insights it offers. Finally, we can speak only to our understanding of practice in Canada. Similar investigations in the US, Europe, Asia and Australia would shed light on the similarities and differences between experiences and actions across space.

\footnotetext{
${ }^{13}$ An opinion by the Federal Trade Commission of the United States, at around the same time, indicates only 700 catalogers (Thompson, 2000). Even so, that is 700 unknown catalogers.
} 
Despite these potential limitations, we feel that we have presented a coherent story and have raised important insights and challenges facing IS researchers and practitioners in the area of information privacy. Our study raises challenges for privacy researchers to explore and critique actual enactments of balance. If the concept of balance is to be taken seriously then the substances employed on the scale must be transparent and fully examined. We also believe there is a need to explore the life of the critical actant in the area of information privacy - the data itself - so that we critically examine organizational statements about the subsequent use of the data.

Our study confirms the need for and benefit of more historical research in MIS. Specifically, there is the benefit of understanding the context of the setting under investigation to appreciate the nuances of the content (Mason, McKenney, \& Copeland, 1997) and the conditions of change and of continuity that accompany the use of IT (Mason et al., 1997). Historical research allows us to evaluate and challenge assumptions and understanding embedded in current research and aspects of our understanding that might not hold when exposed to the light of time. Such assumptions might include inserting an arbitrary divide and treating the Internet as a separable domain of concern for information privacy (Malhorta, Kim, \& Agerwal, 2004) and the use of broad organizational assurances in controlled studies that organizations might not be able to offer in practice (Culnan \& Armstrong, 1999).

Overall we feel that a greater focus on the data in information privacy research is a fruitful and necessary avenue of future research. Such research would be fruitful because it would reveal and generate more knowledge about the travels of data and the unseen actor-networks that emerge around it in different contexts or locations. Such research is necessary if we are going to continue to appeal to the metaphor of balance. Balance has no meaning except in enactment, and if enactments are in practice unbalanced, then the metaphor and the discourse around it appear unjustified. This sort of research would be difficult in purely private sector organizations, because public records about their activities are often unavailable. Yet, where private sector firms use public sector data, as is the case here, the transparency required of public bodies may reveal what otherwise remains unknown, unseen and unacknowledged.

For practitioners, we feel that our research provides some practical insights into understanding the complexity of contemporary privacy issues by framing them in historical context, revealing a rich interplay of influences that shape current issues but are often obscured by our focus on the immediate present. The interpretation of these insights in the unique circumstances facing individual practitioners could lead to alternative visions of the nature of the problem, and through this, alternative solutions. For instance, it is possible that the difficulty that some organizations face in articulating and defending current organizational practices around personal data is that some of those practices are relics from the past whose value and purpose are not locally or broadly understood within the organization. It is also possible that difficulty in defining and defending practices publicly arise from organizational uncertainty around the networks associated with the organization that have aligned around the data. If this were discovered to be the case, these would be actionable items derived from the contextual understanding of a current issue and are examples of the potential that historical research offers practitioners.

\section{References}

Alberta Hansard (1972). Alberta Hansard, March 24, 1972. Edmonton: Alberta Legislature.

Alberta Legislature (1998). Freedom of Information and Protection of Privacy Act Review Committee, October 5, 1998. Edmonton: Government of Alberta.

Bennett, C. J. (1990). The formation of a Canadian privacy policy: The art of and craft of lesson drawing. Canadian Public Administration, 33(4), 551-570.

Bloom, P. N., Milne, G. R., \& Adler, R. (1994). Avoiding misuse of new information technologies: Legal and societal implications. Journal of Marketing, 58(1), 98-124.

Bonner, W. T., \& Chiasson, M. W. (2005). If fair information principles are the answer, what was the question? An actor-network theory investigation of the modern constitution of privacy. Information and Organization, 15(4), 267-293.

Canadian Credit Men's Trust Association Limited (1958). Wiggins Systems Limited, dated January 9, 1958. Company's Office in Winnipeg, Winnipeg, Manitoba.

Canadian Standards Association (2008). About the privacy code. Canadian Standards Association. <http://www.csa.ca/ standards/privacy/Default.asp?language=english $>$.

Cespedes, F. V., \& Smith, H. J. (1993). Database marketing: New rules for policy and practice. Sloan Management Review(Summer), 7-22. 
Clarke, R. A. (1988). Information technology and dataveillance. Communications of the ACM, 31(5), 498-512.

Clarke, R. A. (1999). Internet privacy concerns confirm case for intervention. Communications of the ACM, 42(2), 60-67.

Copithorne, C. (1972). Response to letter from Mr. Heil. May 16, 1972. Public Archives of Alberta, Accession No. 76.346, File/item No. 50100, Box 32, Edmonton.

Culnan, M. J. (1993). 'How did they get my name?' An exploratory investigation of consumer attitudes toward secondary information use. MIS Quarterly, 17(3), 341-363.

Culnan, M. J., \& Armstrong, P. K. (1999). Information privacy concerns, procedural fairness, and impersonal trust: An empirical investigation. Organization Science, 10(1), 104-115.

Culnan, M. J., \& Bries, R. J. (2003). Consumer privacy: Balancing economic and justice considerations. Journal of Social Issues, 59(2), 232-342.

Department of the Provincial Secretary (1928). Reconciliation of deposits and treasury receipts, for the period January 1-April 30, 1928. Motor Vehicle Branch, Government of Saskatchewan, Regina.

Equifax Canada (1993). Consumer information and privacy: The Equifax Canada perspective. January, 1993.

Flaherty, D. H. (1972). Privacy in colonial New England. Charlottesville: University Press of Virginia.

Fournier, S., Dobscha, S., \& Mick, D. G. (1998). Preventing the premature death of relationship marketing. Harvard Business Review(January-February), 42-51.

Foxman, E. R., \& Kilcoyne, P. (1993). Information technology, marketing practice and consumer privacy: Ethical issues. Journal of Public Policy and Marketing, 12(1), 106-119.

Heil, J. P. (1968). A letter to the Minister of Highways (Gordon Taylor) explaining uses made of MVR data by R.L. Polk E' Co. (Canada) Ltd., dated May 27, 1968. Public Archives of Alberta, Accession No. 76346, File/item No. 50100, Box 32, Edmonton.

Heil, J. P. (1972). May 9, 1972 letter from VP of R.L. Polk (Canada) Ltd. listing every mailing made into Alberta in 1971. Public Archives of Alberta, Accession No. 76.346, File/item No. 50100, Box 32, Edmonton.

Heil, J. P. (1973). April 30, 1972 letter from VP of R.L. Polk (Canada) Ltd. about an interpretation of a contract clause. Public Archives of Alberta, Accession No. 76.346, File/item No. 50100, Box 32, Edmonton.

Hogg, B. (1985). History of the Motor Vehicle Division. Alberta Government Services, Edmonton (unpublished).

Hohol, D. A. E. (1972). March 22, 1972 letter Re: Low cost, cash value life insurance. Public Archives of Alberta, Accession No. 76.346, File/item No. 50100, Box 32, Edmonton.

Holmstrom, J., \& Stadler, F. (2001). Drifting technologies and multi-purpose networks: The case of the Swedish cashcard. Information and Organization, 11(3), 187-206.

Koziak, J. (1972). August 24, 1972, letter from Cummins Diesel regarding automobile registration data. Provincial Archives of Alberta, Accession No. 76.346, File/item No. 50100, Box 32, Edmonton.

Latour, B. (1987). Science in action: How to follow scientists and engineers through society. Cambridge: Harvard University Press.

Latour, B. (1988). The pasteurization of France. Translated by A. Sheridan J. Law. Cambridge: Harvard University Press.

Latour, B. (1990). Drawing things together. In M. Lynch \& S. Wolgar (Eds.), Representation in scientific practice (pp. 19-68). Cambridge, Mass: The MIT Press.

Latour, B. (1991). Technology is society made durable. In J. Law (Ed.), A sociology of monsters: Essays on power, technology and domination (pp. 103-131). London: Routledge.

Latour, B. (1992). One more turn after the social turn. In E. McMullin (Ed.), The social dimensions of science (pp. 272-295). Notre Dame: University of Notre Dame Press.

Latour, B. (1993). On technical mediation. In The messenger series on the evolution of civilization, Working paper series. Cornell University, Institute of Economic Research.

Latour, B. (1999a). On recalling ANT. In J. Law \& J. Hassard (Eds.), Actor network theory and after (pp. 14-25). Oxford: Blackwell Publishers.

Latour, B. (1999b). For David Bloor...and beyond: A reply to David Bloor's 'anti-latour'. Studies in the History and Philosophy of Science, 30(1), 113-129.

Laudon, K. C. (1986). Markets and privacy. Communications of the ACM, 39(9), 92-104.

Macavinta, C. (1999a). Privacy advocates rally against DoubleClick, C|NET news.com, November 22, 1999. <http://www.news.com/ Privacy-advocates-rally-against-DoubleClick-Abacus-merger/2100-1023_3-233413.html> Verified 11.03.08.

Macavinta, C. (1999b). DoubleClick, Abacus merge in \$1.7 billion deal, C|NET news.com, November 24, 1999. <http:// netscape.com.com/DoubleClick,+Abacus+merge+in+1.7+billion+deal/2100-1023_3-233526.html> Verified 11.03.08.

Malhorta, N. K., Kim, S. S., \& Agerwal, J. (2004). Internet users' information privacy concerns (IUIPC): The construct, the scale and causal model. Information Systems Research, 15(4), 336-355.

Mason, R. O. (1986). Four ethical issues of the information age. MIS Quarterly, 10(1), 5-12.

Mason, R. O., McKenney, J. L., \& Copeland, D. G. (1997). Developing an historical tradition in MIS research. MIS Quarterly, 21(3), 257-278.

McGrath, K. (2002). The golden circle: A way of arguing and acting about technology in the London ambulance service. European Journal of Information Systems, 11(4), 251-266.

Office of the Information and Privacy Commissioner and the Auditor General of Alberta (1998). Alberta registries: Report to the minister of municipal affairs. Edmonton, Alberta.

Office of the Information, Privacy Commissioner (1999). Annual report to the legislature. Edmonton, Alberta: Government of Alberta.

Organization for Economic Co-Operation and Development (1980). Guidelines: On the protection of privacy and transborder of personal data. Paris: Organization for Economic Co-Operation and Development.

Royal Bank of Canada (2007). Privacy protection in Canada. <http://www.royalbank.com/privacy/protection.html> Verified 10.03.07.

Rule, J., McAdam, D., Stearns, L., \& Uglow, D. (1980). The politics of privacy: Planning for personal data systems as powerful technologies. New York: Elsevier.

Schoeman, F. (1984). Privacy: Philosophical dimensions of the literature. In F. D. Schoeman (Ed.), Philosophical dimensions of privacy (pp. 1-33). London: Cambridge University Press.

Schwartz, B. (1968). The social psychology of privacy. The American Journal of Sociology, 73(6), 741-752. 
Scott, S. V., \& Wagner, E. L. (2003). Networks, negotiations and new times: The implementation of enterprise resource planning into an academic administration. Journal of Information Technology, 17(2), 285-313.

Select Special Freedom of Information and Protection of Privacy Act Review Committee (1999). Final report. Edmonton: Legislative Assembly of Alberta.

Shapiro, S. (1988). Places and spaces: The historical interaction of technology, home and privacy. The Information Society, 14(4), 275-284.

Simpson, R., Ludwig, A., Miller, D., Werry, L. F., Switzer, W., \& Copithorne, C. A. (1970). Report to the Alberta legislature of the special committee on invasion of privacy. Edmonton: Alberta Legislature.

Smith, H. J. (1993). Privacy policies and practices: Inside the organizational maze. Communications of the ACM, 36(12), 105-122.

Solicitor General's Department (1979). Legal research project. Government of Alberta, June 1979 report. Public Archives of Alberta, Accession No. 93.191, Item/file No. 23, Edmonton.

Solove, D. J. (2007). I've got nothing to hide' and other misunderstandings of privacy. San Diego Law Review, 44, 745-768.

Stewart, K. A., \& Segars, A. H. (2002). An empirical examination of the concern for information privacy instrument. Information Systems Research, 13(1), 36-49.

Taylor, G. E. (1968). April 18, 1968, Note for file. Public Archives of Alberta, Accession No. 76.346, File/item No. 50100, Box 23, Edmonton.

Taylor, G. E. (1969). March 21, 1969, Minister of Highway's response to Mrs. H.G. Moore of Medicine Hat. Public Archives of Alberta, Accession No. 76.346, File/item No. 50100, Box 23, Edmonton.

Thompson, M. V. (2000). In the matter of Trans Union Corporation, Docket 9255. Federal Trade Commission (US), March 30, 2000. Washington.

Time Magazine (1968). Counting the house. Time Magazine, Friday, November 8, 1968.

Warren, S. D., \& Brandeis, L. D. (1890). The right to privacy. Harvard Law Review, 4(5), 193-220.

Westin, A. F. (1967). Privacy and freedom. New York: Atheneum.

Wiggins Systems Limited (1951). Wiggins Systems Limited mailing list, January 23, 1951. Provincial Archives of Saskatchewan, Reference No. RE 15, Regina.

Winner, L. (1996). Who will we be in cyberspace? The Information Society, 12, 63-72. 